\title{
Optimal Energy Management Strategy for a DC Linked Hydro-PV-Wind Renewable Energy System for Hydroelectric Power Generation Optimization
}

\author{
Adel Elgammal and Curtis Boodoo
}

\section{ABSTRACT}

\begin{abstract}
The goal of this article is to create an intelligent energy management system that will control the stand-alone microgrid and power flow of a grid associated that includes Battery Energy Storage System, Fuel Cell, Wind Turbine, Diesel Generator, Photovoltaic, and a Hydro Power Plant. Storage systems are required for high dependability, while control systems are required for the system's optimum and steady functioning. The control, operation, and planning of both energy demand and production are all part of energy management. By controlling unpredictable power and providing an appropriate control algorithm for the entire system, the suggested energy management strategy is designed to handle diverse variations in power demand and supply. Under the TOU Tariff, the problem is presented as a discrete time multi-objective optimization method to minimize grid imported energy costs. It also maximizes earnings from surplus RE sales to the grid at a pre-determined RE feed-in tariff. Simulations were run using SIMULINK/MATLAB to validate and evaluate the suggested energy management approach under various power demand and power supply scenarios. The simulations indicate that the proposed energy management can fulfill demand at all times utilizing unreliable renewables like wind, solar, and hydroelectric power plants, as well as hydrogen fuel cells and batteries, without affecting load supply or power quality.
\end{abstract}

Keywords: Integrated system, renewable system, fuel cell, control algorithm, optimization, hybrid system, energy management system, Micro Hydropower Plant.
Published Online: August 25, 2021

ISSN: $2736-5506$

DOI :10.24018/ejenergy.2021.1.3.16

\section{Adel Elgammal*}

The University of Trinidad and Tobago UTT, Utilities Engineering, Point Lisas Campus, Trinidad and Tobago.

(e-mail: adel.elgammal ${ }^{@}$ utt.edu.tt) Curtis Boodoo

The University of Trinidad and Tobago UTT, Utilities Engineering, Point Lisas Campus, Trinidad and Tobago.

(e-mail: curtis.boodoo@utt.edu.tt)

*Corresponding Author

\section{INTRODUCTION}

In the twenty-first century, photovoltaic (PV), wind power, and hydropower power generating exploded in popularity. The continual growth of society and economy, as well as the enhancement of people's living conditions, has resulted in a rise in energy consumption [1]. The approach of aggressive renewable energy development reduces greenhouse gas emissions and air pollution by utilising RES such as hydropower, wind, and solar amongst other. It also contributes to the creation of an ecological society by ensuring energy supplies, improving energy configuration, and ensuring energy supplies [2]. RES fluctuates because to the nature of the climate. Generation uncertainty can affect up to $70 \%$ of solar capacity throughout the day and 100 percent of wind power on quiet days due to passing clouds. This is far greater than the $1 \%$ demand variations that system operators have to deal with. It will necessitate a more sophisticated frequency and voltage control mechanism. The more RE entrants there are, the more difficult (and often impossible) it is to tackle this problem [3]. The output of PV, wind, and hydropower plants is unpredictable, intermittent, and volatile, with no capacity to self-regulate, and the growing grid-connected size of solar and wind power need compensating management. Both pumped-storage power plants and hydropower have high energy storage capacity and regulating ability in the electricity system because they use controlled and flexible power sources. Under a coordinated operating mode of hydro-solar-wind power, the reciprocal complementarity of such power plants with solar and wind power may offer a secure grid connection of renewable power on a larger scale [4]. The availability of wind energy is nondispatch-able, time-dependent, and location-specific. The primary RE, such as PV and wind, have grown their proportion in the generating mix as the need for energy grows and traditional sources become depleted. The most efficient resource use, along with a prediction of load and renewable resources, ensures a considerable decrease in the operation's net cost [5]. Modular hybrid power sources with reserve as a backup at the load centre convert a unidirectional power flow scenario with distributed generating into a bidirectional power flow scenario. The implementation of sophisticated control methods in a distributed control or centralised system controller can improve the performance of such systems. When linked to the grid, they can help the system deal with power quality concerns while also maximising the usage of renewable energy [6]. 
The power system stability control strategy, real-time dispatching control strategy, day-ahead dispatching mode, and yearly dispatching plan are all part of the dispatching and operating strategy for wind-hydro-solar multi-energy complementary operation. The manner of multi-energy complementary functioning of wind-hydro-solar is critical. Study on dispatching policy optimization of wind-hydrosolar complementation power station should be performed under conditions such as flood prevention requirements, compensation benefit of cascade reservoirs, market consumption limitation, power transmission channels, and characteristics of hydro-solar-wind complementary operation. The goal of this research is to adjust the complete dispatching of several priorities and dispatching levels of hydro, PV, and wind energy in order to enhance multi-energy complementation power plant operation management. It is critical for enhancing the power generating advantage of multi-energy complementation power plants, ensuring grid safety, and raising the rate of hydro-solar-wind energy usage [7].

The dispatching of hydro-solar-wind-complementation systems becomes more difficult than that of typical hydropower systems with the addition of solar/wind new energy. This should meet not only the ecological water of the riverway, urban living water supply, flood prevention and control, and power load need, among other things, but also complimentary and matching demand amongst various forms of energy. Furthermore, when total hydro-solar-wind output exceeds power demands, the system must assign surplus hydro, solar, and wind power that would otherwise be demolished in an acceptable way. As a result, a multi-goal, dimensional, and layer intelligent mathematical model of wind-hydro-solar multi-energy complementary operation dispatching optimization is required, in accordance with the features of multi-energy complementation structures. The multi-energy complementary functioning of hydro-solarwind pertains to both the power structure and other resource structures [8]. As a result, systems engineering methods must be used to examine the distribution of load demand in a balanced manner. This will aid in the analysis of various power sources centered on their electric load generation and demand features, such as solar, wind, and hydro power. With the objective of directing the operation of all elements of the multi-energy complementation system, these approaches should also be utilized to design suitable short-term, in-plant and long-term dispatching policies. These should also serve as a solid foundation for operating a power system that is ecologically friendly, cost-effective, and safe [9].

With a significant quantity of data being collected on the same platform, advancements in intelligent monitoring structures are at heart of hybrid system's intelligent dispatching. This information is collected to allow for correlated and integrated monitoring of hybrid outputs, as well as accurate information for big data analysis systems and energy management. Environmental restrictions, load demand, and hybrid outputs, among other things, should be considered into the control strategy and energy management system. This aids in the automated management of hybrid outputs and the maintenance of a real-time load balance for improved hybrid operation and power production efficiency [10]. A big data analytical system should be established to mine data for its in-depth value, and then utilize big data to perform intelligent dispatching, maintenance, operation, and early warning. The development of decision support structures should be encouraged in order to enhance communications and network environment selection, development platform selection, system development mode, generalised template design and development, and prototype structure design and integration methods, as well as to improve the systems' expansion, versatility, interactivity, and practicability [11].

Because hybrid development largely includes hydropower adjustment, cooperation between solar, wind, and hydropower dispatching authority is required to fulfil the aim of dispatching and unified planning. The dispatching centre shall execute hybrid operations in accordance with the dispatching strategy for independent grid connections of solar, wind, and hydropower. Grid dispatch systems may send power-producing jobs to hybrid dispatched systems for a hybrid link with the grid. The power generation for solar, wind, and hydropower is then planned in accordance with the solar power forecast, forecast of wind power, and hydropower adjustment need. It then uses coordinated control techniques to modify the real-time production of cascade PV power plants, wind farms, and hydropower stations to match the system's power demand [12]. In the last decade, more substantial progress has been made with various storage and source combinations. Wind energy optimization in all aspects for grid integration has been carefully evaluated [13] and found to be successful. In recent years, the control structure and objectives have also evolved. Control elements and dependability difficulties with such sources are examined, in addition to other assessments [14]. The energy management system is a collection of algorithms, devices, and processes for lowering and controlling the cost and consumption of energy needed to meet load's criteria. The majority of energy management structure for renewable energy source is focused with management and flow of efficient battery and power usage for its stability, according to a critical evaluation [15]. A full-fledged control plan, on the other hand, is still to be devised. [16] Suggested an optimum PV system scheduling strategy for reducing time-of-use costs. In [17], demand-side management was centered on a net-zero-energy building. A hardware solution for managing the energy of grid linked $\mathrm{PV} /$ wind system has been created [18]. [19] examines energy management structure for both grids linked hybrid RES and independent RES. EMS based on Fuzzy logic controllers, intelligent methods, and linear programming is examined for several combinations. An EMS for regulating ice storage discharge, light, AC, and end-user building loads with appropriate solar rooftop photovoltaic structures in groups is created in the study [20] to absorb Plug-in Electric Vehicle penetration utilizing actual charging set-ups without delaying Electric Vehicle charging. The energy management structure for a micro-grid with RES was created in [21], and it examines SOC, battery power, and net surplus generation before deciding whether to discharge/charge the battery, decrease photovoltaic production, shed load, or enhance PV production via MPPT to manage load end voltage. In a MG with PV/wind and a flywheel energy storing structure, [22] developed a supervisory control. [23] investigated the energy management structure for a Megawatt-range battery energy 
storing structure using power smoothing, actual grid data for voltage control, and peak load shaving of a distribution transformer. [24] proposes distributed algorithm that prioritises the extraction of renewable energy sources by predicting and monitoring generation and loads online. It aims to increase system stability while lowering costs. [25] described a BMS based on physics centred vanadium redoxflow BESS and lithium-ion (Li-ion) battery models. [26] Shows a VRF storing tool for peak-shaving and frequency control operations. To achieve the needed capacities at grid level demand, several BMSs are required. [27] describes a component of the (EMS) that is used to fulfil particular operational goals. [28] A demand-response and demand-side management study was conducted, which included peak shaving, non-critical load scheduling, and incentive techniques. A hierarchical multi-level decentralised architecture was used to demonstrate an energy management system on a medium voltage network with multiple MGs [29]. A PMS for battery photovoltaic based hybrid AC/DC MGs is provided for both islanded and grid connected modes [30]. It automatically balances power flows and controls bus voltage under various operational conditions. [31] investigates and tests a grid-connected hybrid system with batteries for centralised control in three scenarios. The hybrid system may be used to its full potential thanks to the control method established. To manage a huge volume of data in a short amount of time, centralized control necessitates supercomputing and rapid connectivity. Due to the possibility of a single point assault, this is less reliable. [32] proposes a novel topology for wind/PV. The resources are linked to grid via the single boost converter inverter arrangement in this system. It's suitable for grid-connected RES. The number of DERs is gradually rising as each customer becomes a prosumer [33]. If there is a bidirectional relationship among DERs, this can be used to the most extent possible. A tree like user mode system can be used to create a service-oriented architecture. [34] investigates the managing of fuel cell based on proton exchange membrane using a PV/wind combination. [35] proposes a grid linked photovoltaic/wind system. The radial basis function network-sliding mode is used to regulate wind turbine pitch. The generic regression neural network is utilized for photovoltaic system MPPT. The frequency and voltage at point of mutual coupling are regulated using PID and proportional integral (PI) controllers based on the firefly algorithm [36]. Particle swarm optimization for PID outperforms fractional order PID battery charge controllers and modified adaptive accelerated PSO, according to [37]. This form of control is more adaptable since it combines dispersed and centralized control. [38] looked at a supervisory model predictive control (MPC) system that was built in a distributed architecture using two geographically dispersed photovoltaic and wind substructures. In a direct current power grid with the local load associated, each of these subsystems has storage [39]. A direct control system in hybrid direct current/alternating current system is designed for $\mathrm{PV} /$ wind with fuel cell that employs a compensated voltage and harmonic virtual impedance loop.

In this article, an intelligent EMS was designed to meet load demand by maximizing the usage of RES while minimizing the usage of diesel generators. The supervisory control's major goal is to allocate the sources appropriately so that the hybrid energy system can meet the demand of all loads. The controller shifts the batteries into charging mode when there is additional power from sources. When there is an energy shortage from resources, the controller switches the batteries to discharging mode. The hybrid controller only turns on a diesel generator when RES (Wind/PV/Hydro), including the battery bank, cannot meet the demand. The goal is to optimize the usage of RE while minimizing the usage of the diesel producer. This reduces the amount of time the diesel generator is in use, lowering the hybrid energy system's operating costs and polluting emissions.

\section{HYBRID POWER GENERATION SYSTEM CONFIGURATION}

The paper's renewable centered hybrid energy structure is made up of FC, BESS, WT, PV, and Micro Hydro power plants provided by energy service providers. Figure 1 depicts the conceptual framework of the suggested hybrid system in this research. Because of their differences, the operation of various energy supplies in hybrid power is susceptible to distinct limitations in day-ahead scheduling. The key to the optimal functioning of a hybrid energy system is to discover a means to optimise Micro Hydro power output, solar and wind power at the lowest cost since renewable resources are inherently stochastic. Creating an effective scheduling approach to guarantee the power balance of the power system while taking into account water, solar, wind, and other forms of energy with the help of the BESS and hydroelectric power plant is a significant issue to be handled in this situation. To manage the power flow and maintain a unique integrated energy source that comprises fuel cells, battery storage, wind turbines, PV panels, and a hydro power plant, an intelligent system is needed. The integration of various resources, for example Solar-battery-wind-PV-Fuel-Cell, and hydro power plants, will result in increased work efficiency. However, in order for all of these subsystems to work efficiently and fulfill power demands while taking into consideration the changing nature of RES and changes in demand, a power management system is required. As a result, a power management structure with a specialized algorithm (control methods) is required to govern the power flow between such subsystems. Three successful energy management strategies for a freestanding combined battery/wind/PV/Hydro/fuel cell system are discussed. Also discussed is a power management control technique for a freestanding combined battery/wind/PV/Hydro/fuel cell system. RES such as solar, wind, and hydro have been designated as major power sources, while a fuel-cell component has been placed as a backup energy source. The study's energy management strategy emphasizes on the energy produced by RES including wind, solar, and hydro, as well as the battery storage level of charge. This article described a supervisory control system for a Wind Hydro/Photovoltaic/Diesel hybrid power generating structure with energy storage that monitors its operations. The controller was designed to coordinate when power should be produced by RE (wind turbines, solar panels, and hydropower plants) instead of generated by a diesel generator. It goal is to maximize the usage of RE while restraining the usage of diesel generators. Only when demand cannot be satisfied by RES, such as a battery bank, is a diesel 
generator used. Data flow diagrams are used to depict the structural analysis of supervisory control in detail. The hybrid controller was found to distribute the sources appropriately based on availability and demand. To control the electricity from RES for example wind, PV, and hydro, three techniques were used. The following is a list of them: Mode 1- When the battery state of charge is between the RES and positive limits, the battery storage drains, and the surplus power is channeled to run the electrolyser. When the battery storage is at its lowest level of charge and there is no surplus energy available from RES, the fuel-cell sends energy to the load while also charging the battery storage. Mode 2 - the fuel-cell will not work if the battery charging is between a positive limit and extra energy is not available from RE. The battery storage will be drained in this situation. If the battery storage's charge level falls below a certain threshold, the fuel-cell will charge it. Mode 3 - The electrolyser will function and charge the battery storage when the battery charging is between a positive limit and RES provide extra energy. When the battery storage charging falls below the limitations, or when surplus power from RES (wind, solar, and hydro) becomes unavailable, the fuel-cell component kicks in and the battery is drained. This article's management approach for the proposed intelligent power management algorithm of the combined fuel cell/battery/wind/PV/Hydro system is as follows. It will be used to effectively control and plan the supply of energy. The extra power supplied by RES is utilised to charge the batter when it exceeds the power required to satisfy the load requirement. When the load demand exceeds the RES power supply, the battery will be utilised to meet the load demand until it is reduced to a minimal level. If the power outage continues, the fuel-cell will be used to cover the shortfall load while also charging the battery storage. The objective of this project is to develop power management structure model for an integrated fuel cell/battery/wind/PV system that includes a decision strategy (for increased efficiency and flexibility) as well as control modalities for system operation. A variety of variables such as back-up fuel cell status, battery state of charge, load power, Wind, photovoltaic, and Micro hydro power plant output were calculated a simulation time-step input $\Delta \mathrm{t}$ (considered as 1 hour). The operating strategy of the Micro hydro/photovoltaic/Wind/Battery/Fuel Cell integrated system is indicated by a battery energy balance: discharge (energy balance negative) or charge (energy balance positive). The fuel cell is started if the State of Charge drops below the beginning threshold, and it is halted if the SOC exceeds the stopping threshold. To calculate the various energy fluxes in the system, the discharge and charge timings should be approximated on simulation time-step. Battery and Fuel cell parameters, such as the maximum and minimum SOC, are frequently set to a fixed value. These settings are configurable in this project (changeable). The charging mode in a fuel cell storage system is producing hydrogen fuel from the extra electricity and/or in charge of charging the batteries.

The excess electricity is directed to the batteries, which are recharged before the residual power is routed to water electrolysis. To assist with the load, the discharge mode drains the batteries or supplies electricity from a hydrogen fuel cell. The energy storage system is supplied with electricity is given by:

$$
\pm P_{E S S} \pm P_{F C}=P_{H y d r o}+P_{P V}+P_{\text {wind }}-P_{L}
$$

where $\mathrm{P}_{\mathrm{Wind}}$ denotes wind power and $\mathrm{PD}$ denotes demand power, $\mathrm{P}_{\mathrm{PV}}$ denotes photovoltaic power, $\mathrm{P}_{\mathrm{Hydro}}$ denotes micro hydro power, and $\mathrm{P}_{\mathrm{ESS}}$ denotes power to the energy storing structure. $\mathrm{P}_{\mathrm{ESS}}$ can be either a positive (overabundant) or negative (insufficient) power. The simulation's foundation is the integrated RE model to be detailed. Aside from exact optimization, the model's quality, and accuracy, as well as its usage in the method, have a major influence on the utility of simulation results. Figure 1 depicts the framework of an integrated RES. The fuel cell kicks in when renewable energy and the battery are inadequate to fulfill the load, or when the battery charging falls below a specific threshold. When there is enough power from RE and the battery to meet the load demand, or when the battery has attained an acceptable level of charge, the fuel cell shuts off. Figure 2 depicts the method for time-independent Energy Management System setup for the Micro- Battery/Wind/PV/Hydro/Fuel Cell Integrated Renewable System and its system operation`s mode of control utilised in the simulation. Technical data from all of the energy system's components is input into the software. The water flow rate, environmental factors, load demand, and restrictions on the functioning of the energy system are among the data. The total power produced by A Fuel Cell, wind turbine, PV cells, and Micro hydro at hour $\mathrm{t}$ is computed using:

$P(t)=P_{H y d r o}+P_{P V}+P_{\text {wind }} \pm P_{F C} \pm P_{B E S S}$

Various scenarios may arise during the operation of the combined Fuel Cell/Battery/Wind/PV/Micro hydro system: The total energy provided by Wind/PV/hydro might be less than the load demand $\mathrm{P}_{\mathrm{L}}(\mathrm{t})$. After determining the maximum charged energy in the battery bank $E_{\text {char }} \max (t)$ as a precursor, the surplus energy is stored in the batteries $E_{\text {char. }}$ If there is a surplus of energy, it is channeled to hydrogen fuel production by water electrolysis. The total energy provided by the Wind/photovoltaic/hydro system could not be enough to meet the load's requirement. $E_{\text {disch }}$ calculates the maximum amount of energy that may be drained from the battery $E_{\text {disch }}$ $\max (\mathrm{t})$ as a preliminary calculation. The battery capacity remains constant if the total energy produced by Wind/Photovoltaic/hydro is equal to the load demand. The total energy provided by Wind/Photovoltaic/hydro, as well as the energy stored in $\mathrm{E}_{\mathrm{disch}}$ batteries, may not be sufficient to meet load requirement. The fuel cell should be able to manage load in this situation. A pre-programmed control strategy is set when the system is installed and comprises of preprogrammed control parameters. To determine whether to turn on the fuel cell or not, particular criteria characterizing the system status are used. As a result, an intelligent Energy Management System for a Battery/Fuel Cell/Wind/PV/Hydro Structure was created. It was utilized to gather data on energy generation from various components of the integrated renewable system and estimate the load that needed to be powered. The intelligent energy management system of the integrated renewable system runs on a sliding control, with the Micro hydro power plant as a major source of energy. PV and wind energy production serve as secondary sources of 
energy, with the battery serving as a complement and the fuel cell serving as a backup. When there is a surplus of RE, the charging mode is enabled. The IPMS is in charge of making and implementing the decision to distribute surplus electricity. This extra power is assigned to the battery controller via the Energy Management System. The hydrogen controller directs the remaining electricity from the battery to water electrolysis once it has been fully charged. When energy is requisite to meet the load, the discharging mode is triggered. The Energy Management System makes the choice to distribute the needed electricity in this scenario. The battery controller determines if the battery can handle the load by requesting the needed power from the battery. If the battery cannot manage the load, the load will be distributed to the fuel cell while the hydrogen controller charges the battery. The fuel cell is designed to deliver just $5 \mathrm{~kW}$ when it is used. The system switches between several means depending on the amount of energy required by load and the quantity of energy available from each of the sources. The flow of information between the various modalities is depicted in Fig. 4. To begin, the power produced by the micro hydro power plant, wind turbine and PV panels is assessed for every hour annually and kept in matrices, making electricity available in each hour easily retrievable. The energy provided by the micro hydro power plant fully satisfies the load requirement while the system is in mode 1. In this mode, the PV panels and wind turbines are connected to the system but are not used to meet the load. Rather, the wind turbine's energy will be combined with any excess energy from the PV panels to charge the batteries and/or create hydrogen fuel. When the electricity provided by the micro hydro power plant is insufficient to meet load, the system switches to mode 2 . If the combined energy from the wind turbine and PV panels exceeds the load's requirements, the micro hydro power plant's sufficient power is used to meet the demand. Sliding control is used to match the power requirements of the wind turbine and PV panels to the load's power demand. Similar to mode 1, the extra energy from the wind turbine may be utilized to charge the batteries and/or produce hydrogen fuel. However, if the quantity of power required by the load cannot be given by mode 2 , the software selects whether element (batteries or fuel cell) takes precedence in terms of energy supply. The programme decides which element gets precedence in terms of supplying energy: The battery will be used if the charge level is more than lowest (40 percent) and the battery is capable of delivering energy to the load. If the micro hydro power plant, PV panels, and wind turbine combined power is insufficient to meet the load, and the battery is at its lowest charge and therefore unable to fulfil the demand, the fuel cell will be used to meet the demand and charge the battery. Micro-hydro turbine, wind turbine, and PV power flows are indicated by PHydro, PWT, and PPV respectively. The combined power flow from the wind and micro hydro generator largely meets the load power requirement, $\mathrm{P}_{\mathrm{L}}(\mathrm{t})$. When the renewable onsite generator is inadequate to meet the load demand, $\mathrm{P}_{\mathrm{DRE}}$ $\mathrm{L}(\mathrm{t})$ is supplemented by electricity purchased from the grid; $\mathrm{P}_{\mathrm{G}-\mathrm{L}}(\mathrm{t})$ is used when the renewable on-site generator is insufficient to satisfy the load need. $P_{\text {DRE-G }}(t)$ is sold to the grid at a fixed feed-in tariff when on-site renewable generation exceeds load demand. The suggested strategy attempts to minimize grid energy expenditures while maximizing money over a 24 -hour control period, earned by the sale of surplus DRE to the grid. In the discrete time domain, the optimization issue is stated as follows:

$\min J_{1}=\sum_{1}^{n} \rho_{g}(k) P_{G-L}(k)$

$\max J_{2}=\sum_{1}^{n} \rho_{f}(k) P_{D R E-G}(k)$

$\min J_{e}=t_{s}\left(\alpha_{1} \sum_{1}^{n} \rho_{g}(k) P_{G-L}(k)-\alpha_{2} \sum_{1}^{n} \rho_{f}(k) P_{D R E-G}(k)\right)$

where the weighting components are $\alpha_{1}+\alpha_{2}=1, \mathrm{k}$ is the kth sampling interval, and ts is the sampling period, which in this example is 1 hour. $\rho_{\mathrm{f}}$ represents the feed-in tariff, $\rho_{\mathrm{g}}(\mathrm{k})$ represents the time-of-use price for RE sold to the grid. The total number of samples taken during the control horizon is represented by $n$. The suggested Energy management system maximizes the utilization of on-site produced energy to satisfy system load demand in this optimization scenario. It only exports excess electricity to the grid once the consumer's needs have been met completely. The following restrictions are applied to the solution of the objective functions:

$$
\begin{aligned}
& P_{D R E-L}(k)+P_{G-L}(k)=P_{L}(k) \\
& P_{H y d r o}(k)+P_{W T}(k)+P_{P V}(k) \pm P_{F C}(k) \pm P_{\text {Battery }}(k)=P_{D E R-L}(k)+P_{D E R-G}(k)
\end{aligned}
$$

$P_{H y d r o}^{\min } \leq P_{H y d r o}(k) \leq P_{H y d r o}^{\max }$

$P_{W T}^{\min } \leq P_{W T}(k) \leq P_{W T}^{\max }$

$P_{W T}^{\min } \leq P_{W T}(k) \leq P_{W T}^{\max }$

$P_{F C}^{\min } \leq P_{F C}(k) \leq P_{F C}^{\max }$

$P_{\text {Battery }}^{\min } \leq P_{\text {Battery }}(k) \leq P_{\text {Battery }}^{\max }$

$P_{G-L}^{\min } \leq P_{G-L}(k) \leq P_{G-L}^{\max }$

$P_{D R E-L}^{\min } \leq P_{D R E-L}(k) \leq P_{D R E-L}^{\max }$

$P_{D R E-G}^{\min } \leq P_{D R E-G}(k) \leq P_{D R E-G}^{\max }$

\section{Simulation Results AND Discussion}

As illustrated in Figure 3, a typical peak demand for the load is $55000 \mathrm{~W}$, while the intermediate load is between $44000 \mathrm{~W}$ and $45000 \mathrm{~W}$, allowing the proposed control model to be tested. A $25 \mathrm{~kW}$ micro hydro power plant, $10 \mathrm{~kW}$ fuel cells, $10 \mathrm{kWh}$ battery bank, $15 \mathrm{~kW}$ wind power, $15 \mathrm{~kW}$ PV solar power, and $50 \mathrm{~kg}$ hydrogen tank make up the integrated 
renewable system. To see how the suggested energy management approach manages the power demand discharging, power supply charging and energy flow between various subsystems, simulations were run on control model with actual data of load demand, wind, and solar energies. These data (load demand, solar and wind power) were used to a power system modeled in MATLAB/Simulink to show the correctness of the analysis for more practical findings and a more complete examination of the suggested approach. Table I and Fig. 4-7 illustrate the demand fulfilled by the integrated RES (Wind outputs/ PV/ and Micro hydro) on a typical day. The renewable energy created (addition of Fuel Cell/ Wind outputs/ PV/ and Micro hydro) from RES was estimated as shown in Table I. Table I and Fig. 4-7 demonstrate how the renewable energy system (micro hydro, wind and PV) meets demand, as well as how the sources were assigned based on availability and load demand. It was discovered that there are differences in both source availability and demand. Depending on conclusion mode, the battery or fuel cell compensates for the shortage. Because of the absence of RES, the suggested Energy management structure allocated the battery to provide the load, as seen in the simulation results above. The suggested Energy management system allocated the fuel cell to help the RE in satisfying the load, as shown in the Figures when the RES is at the lowest level. Because renewable energy sources are lacking, the suggested Energy management system uses the fuel cell to help with raising load demand supply (44.467 and $44.667 \mathrm{~kW}$ ). Because RE has a power shortfall, the storage system acts as a supplement. In this example, the load was powered by a RES and a BSS. The simulation results also demonstrate how the suggested Energy management system makes optimal usage of the battery bank. The suggested Energy management structure puts the batteries into charging mode whenever surplus energy from RES is accessible. The energy from the fuel cell is used to fully charge the battery. When battery is 80.30 percent charged, suggested Energy management system shuts off the fuel cell and uses RE (micro hydro, wind, and PV) to meet load demand while also charging the battery. This confirms what was previously stated: When a combination of micro hydro, PV, wind, and battery storage can meet the load requirement, the suggested Energy management system turns off the fuel cell. In summary, the suggested Energy management structure is designed to assure the continuous supply of electricity to the demand while also controlling the operation of RES (micro hydro, Wind, and PV) and BSS (Fuel Cell and Batteries). RE is prioritised for load supply, with any extra energy (if any) flowing into battery storage. When renewable energy (RE) is in low supply of electricity, the storage system acts as a backup. When RES is inaccessible and the battery has attained its minimal level of charging, the fuel cell is employed to help the rising load demand supply while simultaneously charging the battery storage. When the RES and battery state of charge are at their lowest, fuel cells are also employed to help renewable energy in supplying the load. The results demonstrate that the integrated micro-hydro/ fuel cell/ battery/Wind/PV energy management system is capable of supervising, managing, and controlling the integrated renewable energy system.

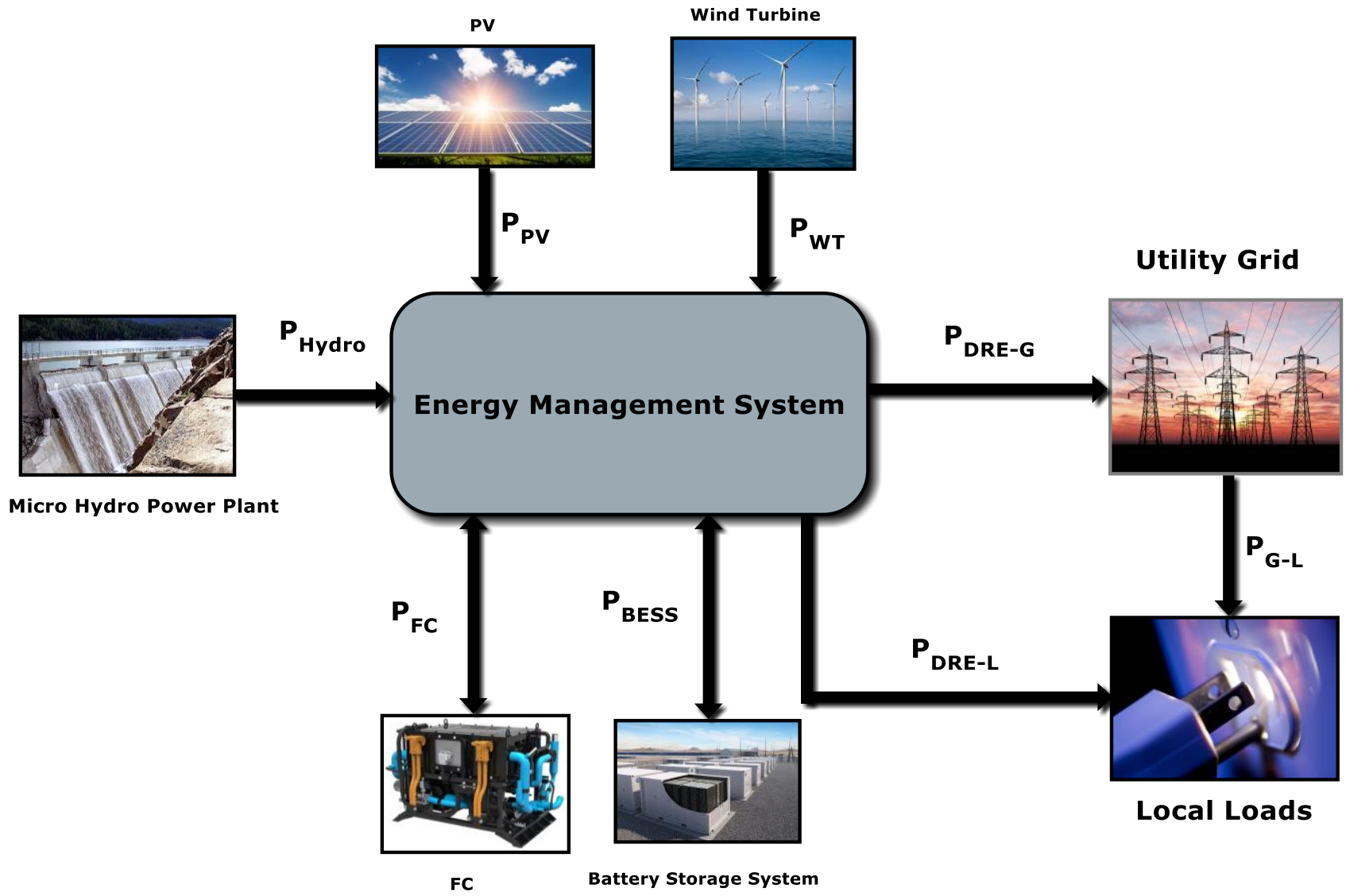

Fig. 1. The grid-connected hybrid system's basic framework with energy flow. 


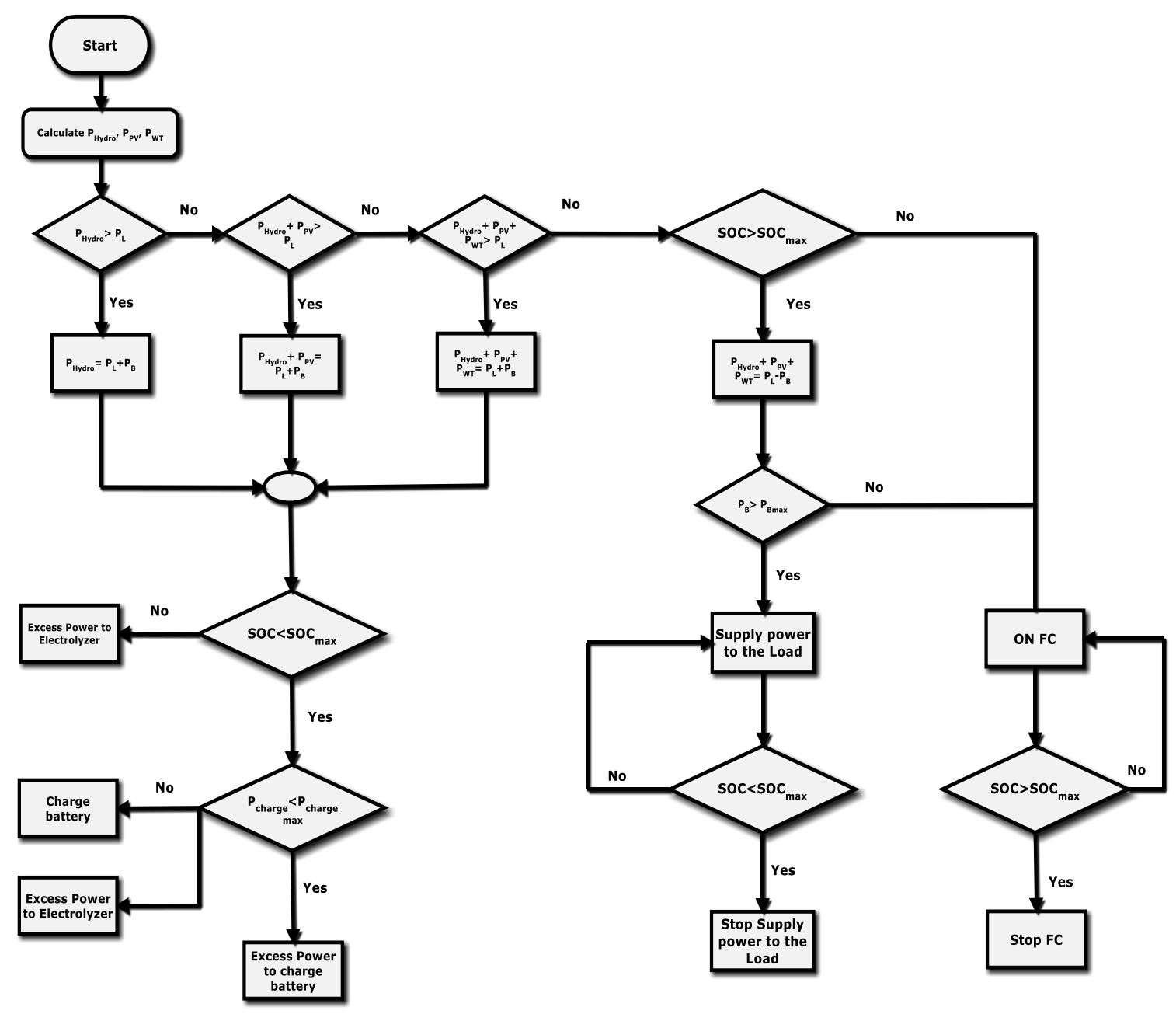

Fig. 2/ The suggested Energy Management System of Control for the Diesel/Wind/PV/Micro-Hydro/Battery Energy System, as well as its modes of operation.

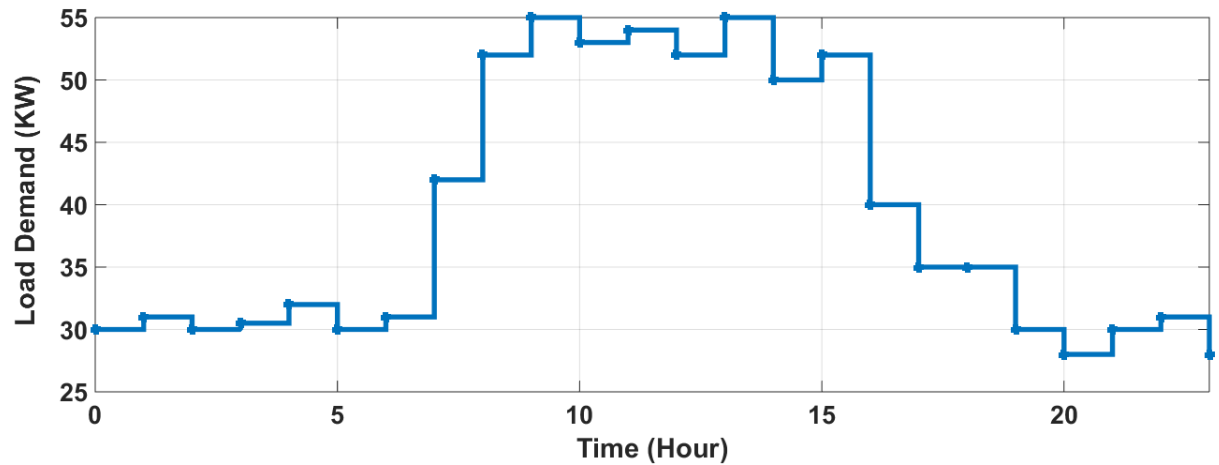

Fig. 3. Daily load demand.

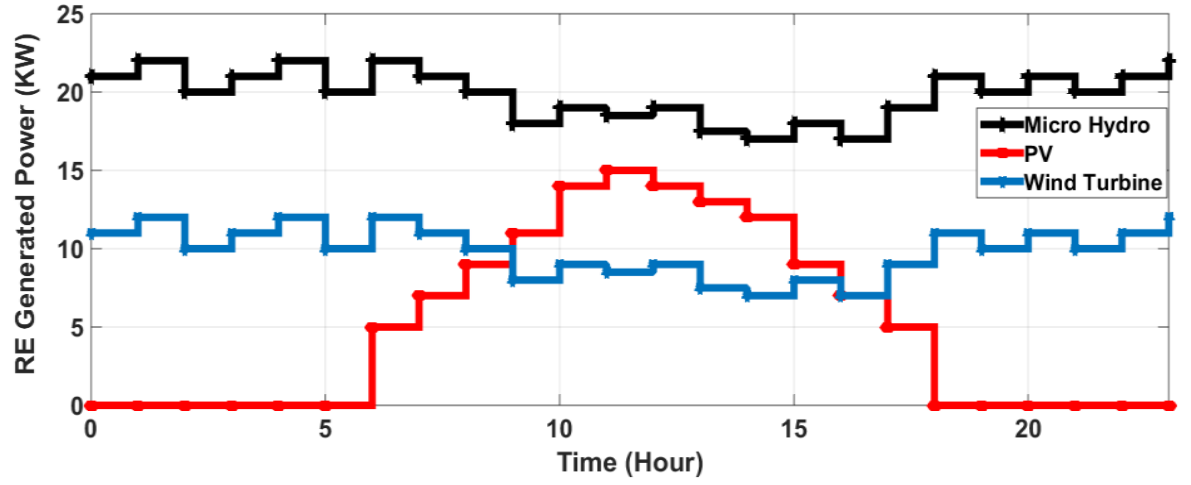

Fig. 4. A typical day's output of renewable resources. 


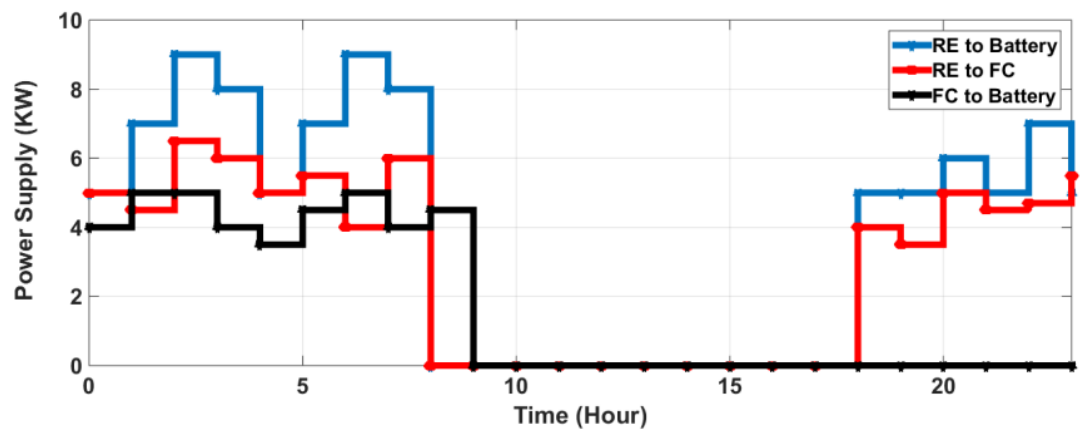

Fig. 5. Renewable Energy Provides Power to Battery and Fuel Cell.

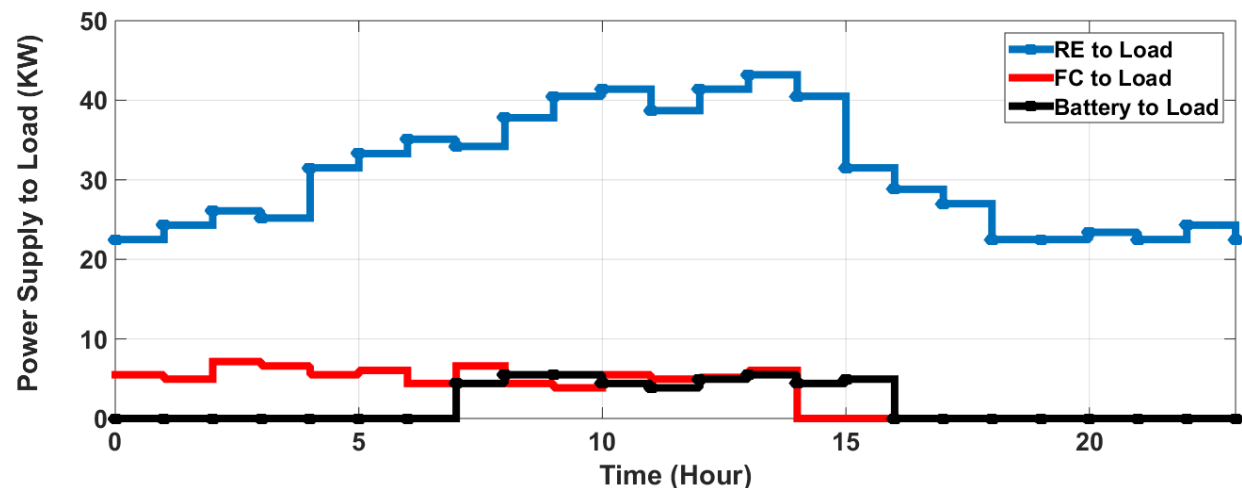

Fig. 6. To meet the load demand, power supplied by batteries, fuel cells, and renewable energy.

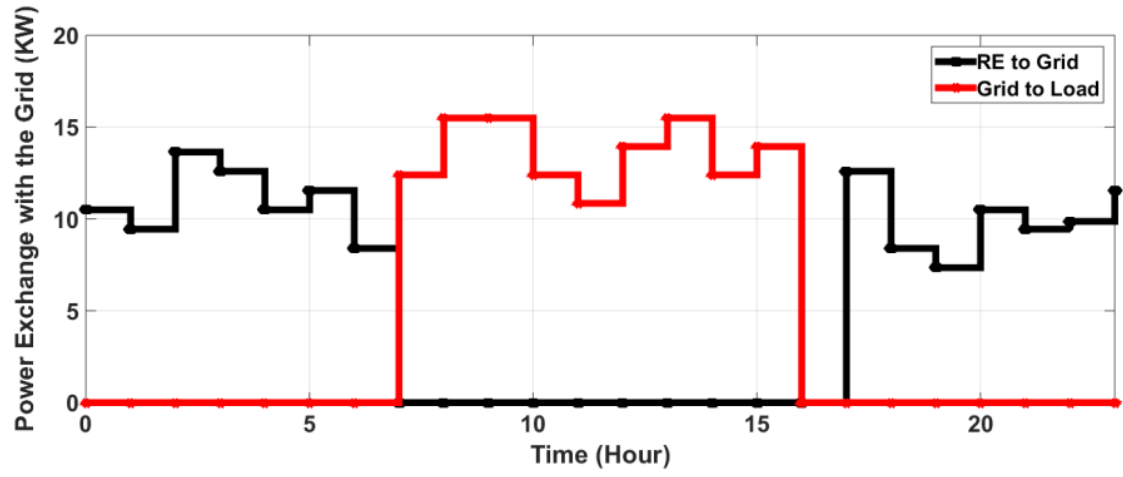

Fig. 7. Grid-supplied/to-grid-supplied power to meet load demand.

TABLE I: THE COMBINED MICRO HYDRO/PV/Wind/FC/BATTERY SYSTEM MEETS CONTRIBUTIONS AND POWER NEEDS

\begin{tabular}{|c|c|c|c|c|c|c|c|c|c|c|c|}
\hline $\begin{array}{l}\text { Time } \\
\text { (h) }\end{array}$ & $\begin{array}{l}\text { Load } \\
\text { PL }_{\mathrm{L}}(\mathrm{t}) \\
(\mathrm{KW})\end{array}$ & $\begin{array}{c}\text { Output } \\
\text { Power of } \\
\text { Micro Hydro } \\
(\mathrm{KW})\end{array}$ & $\begin{array}{l}\text { Output } \\
\text { Power } \\
\text { of PV } \\
(\mathrm{KW})\end{array}$ & $\begin{array}{c}\text { Output } \\
\text { Power } \\
\text { of Wind } \\
(\mathrm{KW})\end{array}$ & $\begin{array}{l}\text { Output } \\
\text { Power } \\
\text { of FC } \\
(\mathrm{KW})\end{array}$ & $\begin{array}{l}\text { RE Energy } \\
\text { Generated } \\
(\mathrm{KW})\end{array}$ & $\begin{array}{c}\text { RE Supplied to } \\
\text { the Load P PRE- } \\
\text { L(t) } \\
(\mathrm{KW})\end{array}$ & $\begin{array}{c}\text { RE } \\
\text { Supplied } \\
\text { to the } \\
\text { Battery } \\
\text { (KWh) }\end{array}$ & $\begin{array}{l}\text { power } \\
\text { purchased } \\
\text { from the } \\
\text { grid } P_{\mathrm{G}-\mathrm{L}}(\mathrm{t}) \\
(\mathrm{KW})\end{array}$ & $\begin{array}{l}\text { power } \\
\text { Sold to } \\
\text { the grid } \\
\text { P }_{\text {DRE-G }}(\mathrm{t}) \\
(\mathrm{KW})\end{array}$ & $\begin{array}{c}\text { Battery } \\
\text { State of } \\
\text { Charge } \\
(\%)\end{array}$ \\
\hline $\begin{array}{l}00: 00 \\
\end{array}$ & 32.98 & 20.82 & 0.0 & 10.82 & 0.0 & 31.98 & 30.98 & 0.0 & 3.82 & 0.0 & 80.82 \\
\hline 01:00 & 31.45 & 20.79 & 0.0 & 10.79 & 0.0 & 30.45 & 30.45 & 0.0 & 4.79 & 0.0 & 80.79 \\
\hline 02:00 & 34.64 & 21.02 & 0.0 & 11.02 & 0.0 & 32.64 & 31.64 & 0.0 & 4.02 & 0.0 & 81.02 \\
\hline 03:00 & 32.51 & 21.84 & 0.0 & 11.84 & 0.0 & 33.51 & 32.51 & 0.0 & 3.84 & 0.0 & 81.84 \\
\hline 04:00 & 33.47 & 20.98 & 0.0 & 10.98 & 0.0 & 32.47 & 31.47 & 0.0 & 3.98 & 0.0 & 80.98 \\
\hline 05:00 & 32.17 & 22.35 & 0.0 & 12.35 & 0.0 & 33.17 & 31.17 & 0.0 & 2.35 & 0.0 & 72.35 \\
\hline 06:00 & 33.98 & 21.85 & 11.20 & 11.85 & 8.20 & 43.98 & 33.98 & 5.20 & 0.0 & 8.20 & 71.85 \\
\hline 07:00 & 32.76 & 21.17 & 11.80 & 11.17 & 8.80 & 42.76 & 32.76 & 6.80 & 0.0 & 9.80 & 71.17 \\
\hline 08:00 & 41.51 & 20.95 & 12.40 & 10.95 & 9.40 & 51.51 & 41.51 & 5.40 & 0.0 & 8.40 & 70.95 \\
\hline 09:00 & 45.74 & 20.25 & 12.98 & 10.25 & 9.98 & 55.74 & 45.74 & 5.98 & 0.0 & 10.98 & 70.25 \\
\hline 10:00 & 50.52 & 19.23 & 14.50 & 9.23 & 10.50 & 60.52 & 50.52 & 7.50 & 0.0 & 11.50 & 79.23 \\
\hline 11:00 & 51.47 & 19.07 & 14.85 & 9.07 & 10.85 & 61.47 & 51.47 & 4.85 & 0.0 & 8.85 & 79.07 \\
\hline 12:00 & 52.26 & 20.25 & 15.12 & 10.25 & 11.12 & 62.26 & 52.26 & 5.12 & 0.0 & 9.12 & 80.25 \\
\hline 13:00 & 51.32 & 20.78 & 15.40 & 10.78 & 10.40 & 61.32 & 51.32 & 5.40 & 0.0 & 7.40 & 80.78 \\
\hline 14:00 & 49.48 & 21.21 & 14.20 & 11.21 & 9.20 & 59.48 & 49.48 & 4.20 & 0.0 & 7.20 & 81.21 \\
\hline $15: 00$ & 50.47 & 20.85 & 13.70 & 10.85 & 8.70 & 60.47 & 50.47 & 3.70 & 0.0 & 6.70 & 80.85 \\
\hline $16: 00$ & 47.59 & 20.02 & 13.10 & 10.02 & 8.10 & 57.59 & 47.59 & 3.10 & 0.0 & 6.10 & 90.02 \\
\hline $17: 00$ & 45.24 & 19.89 & 12.50 & 9.89 & 7.50 & 55.24 & 45.24 & 2.50 & 0.0 & 6.50 & 89.89 \\
\hline 18:00 & 40.28 & 19.12 & 12.70 & 9.12 & 6.70 & 50.28 & 40.28 & 2.70 & 0.0 & 6.70 & 89.12 \\
\hline 19:00 & 30.77 & 20.25 & 0.0 & 10.25 & 6.50 & 30.77 & 28.77 & 0.0 & 3.82 & 0.0 & 90.25 \\
\hline 20:00 & 31.78 & 20.87 & 0.0 & 10.87 & 6.20 & 30.78 & 28.78 & 0.0 & 3.79 & 0.0 & 90.87 \\
\hline 21:00 & 30.47 & 20.02 & 0.0 & 10.02 & 5.70 & 30.47 & 27.47 & 0.0 & 2.02 & 0.0 & 90.02 \\
\hline 22:00 & 31.95 & 19.25 & 0.0 & 9.25 & 5.80 & 29.95 & 26.95 & 0.0 & 2.84 & 0.0 & 89.25 \\
\hline 23:00 & 30.87 & 19.87 & 0.0 & 9.87 & 4.20 & 28.87 & 26.87 & 0.0 & 2.98 & 0.0 & 89.87 \\
\hline
\end{tabular}




\section{CONCLUSION}

Micro-hydro, with its power density compared to other intermittent RES, is an innovative RE concept with enormous potential to lessen reliance on finite fossil fuels. To maintain the continuousness of energy supply to the load and govern the functions of RES (Hydro/ Wind and PV) and BSS, an intelligent energy management method based on MOGA was developed. The model's goal was to fulfil all of the energy demand from on-site renewables while lowering the cost of grid power imports. The proposed energy management approach tackles the issue of power needs by satisfying load demand while maintaining control over power flow. The energy management system guarantees system stability by sending excess power to the storage system. At the same time, it efficiently manages the battery's charging and discharging operations to improve its performance and longevity. Additionally, when a load demand must be met and both the battery charging and the RES are at their lowest levels, the energy management system seamlessly delivers the demand from the fuel cell to prevent system collapses. In this work, microgrid energy management is presented as multi-objective optimization problem and a new multi-objective solution utilising MOGA is provided. The optimization issue includes demand response to illustrate its influence on optimal energy management and techno-commercial advantages. For the most efficient scheduling of battery energy storage systems, a fuzzy interface has been devised. The integrated (Hydro/PV/Wind/Battery/Fuel Cell) system was tested under a variety of operating situations, and the findings verified its competence to regulate it. The ideal capacity of all units, charging/discharging schedule, fuel cost, cost of energy, yearly net present cost, power exchange with grid battery state of charge, power exchange with grid, starting cost, operating cost, and greenhouse gas emission penalty are all calculated using simulations. The examination of the findings given in the study revealed that the suggested model has a significant energy and cost saving potential under TOU pricing. Aside from the anticipated savings, the concept generates additional revenue by selling surplus RE to the grid via a DRE feed-in tariff. To prove the technique's efficacy, simulation results produced with the suggested method are compared to those obtained with other evolutionary algorithms.

\section{REFERENCES}

[1] E.N. Nyeche, E.O. Diemuodeke, "Modelling and optimisation of a hybrid PV-wind turbine-pumped hydro storage energy system for minigrid application in coastline communities" Journal of Cleaner Production, Volume 250, 2020, 119578, ISSN 0959-6526, https://doi.org/10.1016/j.jclepro.2019.119578.

[2] Boualam Benlahbib, Noureddine Bouarroudj, Saad Mekhilef, Dahbi Abdeldjalil, Thameur Abdelkrim, Farid Bouchafaa, Abelkader lakhdari "Experimental investigation of power management and control of a PV/wind/fuel cell/battery hybrid energy system microgrid' International Journal of Hydrogen Energy, Volume 45, Issue 53, 2020, Pages 29110-29122, ISSN 0360-3199, https://doi.org/10.1016/j.ijhydene.2020.07.251.

[3] Oleksandr Riabenko;Oksana Kliukha;Olha YakovlevaHavryliuk;Sergii Osadchyi;Serhii Sunichuk "Increasing the Role of Hydro and Pumped Storage Power Plants in Energy Systems Operation Management" 2020 IEEE 7th International Conference on Energy Smart Systems (ESS).
[4] Vipina Valsan;P. Kanakasabapathy "Smart energy management and control of stand-alone pico-hydro systems" 2017 Innovations in Power and Advanced Computing Technologies (i-PACT).

[5] Vipina Valsan;P. Kanakasabapathy "Design and implementation of smart energy management system for stand-alone micro-hydro systems" 2017 International Conference on Technological Advancements in Power and Energy ( TAP Energy).

[6] F. Fang;R. Karki "Reliability assessment of hydro dominant systems with diurnal energy management" 2017 IEEE Electrical Power and Energy Conference (EPEC).

[7] Somnath Das;Ashok Kumar Akella "A Control Strategy for Power Management of an Isolated Micro Hydro-PV-Battery Hybrid Energy System" 2018 4th International Conference on Electrical Energy Systems (ICEES).

[8] Adel M. Sharaf;Adel A. A. El-Gammal "Optimal PID-self regulating controller for micro hydro-fuel cell green Energy Management Scheme" 2010 IEEE Electrical Power \& Energy Conference.

[9] X.V. Filho;A. Oliveira;Mello JCO;L.A.S. Pilotto;F. Arteiro;M.A.M. Vieira "How to consider reliability aspects in the energy management of the Brazilian hydro dominated system" IEEE PES Power Systems Conference and Exposition, 2004.

[10] Waqas Ahmad;Saqeb Ejaz;Muhammad Naveed Naz;Zubair Yamin;Muhammad Waseem Altaf;Saqif Imtiaz "Micro-Hydro Coordinated Strategy With Battery Energy Storage System Towards Cost Effective Load Management" 2021 International Conference on Emerging Power Technologies (ICEPT).

[11] Adriana C. Luna;Nelson L. Diaz;Moisès Graells;Juan C. Vasquez;Josep M. Guerrero "Mixed-Integer-Linear-ProgrammingBased Energy Management System for Hybrid PV-Wind-Battery Microgrids: Modeling, Design, and Experimental Verification” IEEE Transactions on Power Electronics, Year: 2017 | Volume: 32, Issue: 4.

[12] Adel Merabet;Khandker Tawfique Ahmed;Hussein Ibrahim;Rachid Beguenane;Amer M. Y. M. Ghias "Energy Management and Control System for Laboratory Scale Microgrid Based Wind-PV-Battery" IEEE Transactions on Sustainable Energy, Year: 2017, Volume: 8, Issue: 1 .

[13] Behera S, Sahoo S, Pati BB. A review on optimization algorithms and application to wind energy integration to grid. Renewable and Sustainable Energy Reviews. 2015;48:214-227. DOI:10.1016/j.rser.2015.03.066.

[14] Khare V, Nema S, Baredar P. Solar wind hybrid renewable energy system:A review. Renewable and Sustainable Energy Reviews. 2016;58:23-33. DOI: 10.1016/j.rser.2015.12.223.

[15] Mahesh A, Sandhu KS. Hybrid wind/photovoltaic energy system developments: Critical review and findings. Renewable and Sustainable Energy Reviews. 2015;52:1135-1147. DOI: 10.1016/j.rser.2015.08.008.

[16] Wu Z, Xia X. Optimal switching renewable energy system for demand side management. Solar Energy. 2015;114:278-288. DOI: 10.1016/j. solener.2015.02.001.

[17] Sichilalu SM, Xia X. Optimal energy control of grid tied PV-diesel battery hybrid system powering heat pump water heater. Solar Energy. 2015;115:243-254. DOI: 10.1016/j. solener.2015.02.028.

[18] Li G, Chen Y, Li T. The realization of control subsystem in the energy management of wind/solar hybrid power system. In: 3rd Int. Conf. on Power Electronics Sys. and Applications (PESA); May 2009; Hong Kong, China. 2009. pp. 1-4.

[19] Olatomiwa L, Mekhilef S, Ismail MS. Energy management strategies in hybrid renewable energy systems: A review. Renewable and Sustainable Energy Reviews. 2016;62:821-835. DOI: 10.1016/j. rser.2016.05.040.

[20] Sehar F, Pipattanasomporn M, Rahman S. Coordinated control of building loads, PVs and ice storage to absorb PEV penetrations. International Journal of Electrical Power \& Energy Systems. 2018;95:394-404. DOI: 10.1016/j.ijepes.2017.09.009.

[21] Merabet A, Ahmed KT, Ibrahim H, Beguenane R, Ghias AM. Energy management and control system for laboratory scale microgrid based wind-PV-battery. IEEE Transactions on Sustainable Energy. 2017;8(1):145-154. DOI: 10.1109/TSTE.2016.2587828.

[22] Boukettaya G, Krichen L. A dynamic power management strategy of a grid connected hybrid generation system using wind, photovoltaic and flywheel energy storage system in residential applications. Energy. 2014;71:148-159. DOI: 10.1016/j.energy.2014.04.039.

[23] Reihani E, Sepasi S, Roose LR, Matsuura M. Energy management at the distribution grid using a battery energy storage system (BESS). International Journal of Electrical Power \& Energy Systems. 2016;77:337-344. DOI: 10.1016/j.ijepes.2015.11.035.

[24] Mohamed A, Mohammed O. Realtime energy management scheme for hybrid renewable energy systems in smart grid applications. Electric 
Power Wind Solar Hybrid Renewable Energy System Systems Research. 2013;96:133-143. DOI: 10.1016/j.epsr.2012.10.015.

[25] Lucas A, Chondrogiannis S. Smart grid energy storage controller for frequency regulation and peak shaving, using a vanadium redox flow battery. International Journal of Electrical Power \& Energy Systems. 2016;80:26-36. DOI: 10.1016/j.ijepes.2016.01.025.

[26] Lawder MT, Suthar B, Northrop PW, De S, Hoff CM, Leitermann O, et al. Battery energy storage system (BESS) and battery management system (BMS) for grid-scale applications. Proceedings of the IEEE. 2014;102(6):1014-1030. DOI: 10.1109/jproc.2014.2317451.

[27] Nick M, Cherkaoui R, Paolone M. Optimal allocation of dispersed energy storage systems in active distribution networks for energy balance and grid support. IEEE Transactions on Power Systems. 2014;29(5):2300-2310. DOI: 10.1109/tpwrs.2014.2302020.

[28] Gelazanskas L, Gamage KA. Demand side management in smart grid: A review and proposals for future direction. Sustainable Cities and Society. 2014;11:22-30. DOI: 10.1016/j. scs.2013.11.001.

[29] Vasiljevska J, Lopes JP, Matos MA. Integrated micro-generation, load and energy storage control functionality under the multi micro-grid concept. Electric Power Systems Research. 2013;95:292-301. DOI: 10.1016/j. epsr.2012.09.014.

[30] Yi Z, Dong W, Etemadi AH. A unified control and power management scheme for PV-battery-based hybrid microgrids for both gridconnected and islanded modes. IEEE Transactions on Smart Grid. 2017;9:1. DOI: 10.1109/tsg.2017.2700332.

[31] Abbassi R, Chebbi S. Energy management strategy for a grid connected wind-solar hybrid system with battery storage: Policy for optimizing conventional energy generation. International Review of Electrical Engineering. 2012;7(2):3979-3990.

[32] Singaravel MR, Daniel SA. MPPT with single DC-DC converter and inverter for grid-connected hybrid wind-driven PMSG-PV system. IEEE Transactions on Industrial Electronics. 2015;62(8):4849-4857. DOI: 10.1109/tie.2015.2399277.

[33] Alagoz BB, Kaygusuz A, Karabiber A. A user-mode distributed energy management architecture for smart grid applications. Energy. 2012;44(1):167-177. DOI: 10.1016/j. energy.2012.06.051.

[34] Li X, Jiao X, Wang L. Coordinated power control of wind-PV-fuel cell for hybrid distributed generation systems. In: The SICE Annual Conference; September 2013; Nagoya, Japan: IEEE. 2013. pp. 150 155 .

[35] Hong CM, Chen $\mathrm{CH}$. Intelligent control of a grid-connected wind photovoltaic hybrid power systems. International Journal of Electrical Power \& Energy Systems. 2014;55:554-561. DOI: 10.1016/j.ijepes.2013.10.024.

[36] Chaurasia GS, Singh AK, Agrawal S, Sharma NK. A meta-heuristic firefly algorithm based smart control strategy and analysis of a grid connected hybrid photovoltaic/wind distributed generation system. Solar Energy. 2017;150:265-274. DOI: 10.1016/j. solener.2017.03.079.

[37] Bendary AF, Ismail MM. Battery charge management for hybrid $\mathrm{PV} /$ wind/fuel cell with storage battery. Energy Procedia. 2019;162:107-116. DOI: 10.1016/j.egypro.2019.04.012.

[38] Qi W, Liu J, Christofides PD. Distributed supervisory predictive control of distributed wind and solar energy systems. IEEE Transactions on Control Systems Technology. 2013;21(2):504-512. DOI: 10.1109/TCST.2011.2180907.

[39] Baghaee HR, Mirsalim M, Gharehpetian GB, Talebi HA. A decentralized power management and sliding mode control strategy for hybrid AC/DC microgrids including renewable energy resources. IEEE Transactions on Industrial Informatics. 2017:1-1. DOI: 10.1109/tii.2017.2677943.

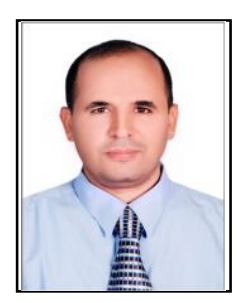

Adel Elgammal is currently an Associate Professor at the University of Trinidad and Tobago UTT, Department of Energy Systems. He received his B.Sc. Degree in Electrical Power Engineering from Helwan University-EGYPT in 1996. He completed his M.Sc. Degree in Electric Drives and Machines Engineering in 2002 and Ph.D. Degree in Jan-2007 from the Faculty of Engineering (Helwan University-EGYPT). In May 2008, Dr. Elgammal joined the University of Trinidad and Tobago (UTT) as an Assistant Professor and then he was promoted to Associate Professor in May 2010 at the Energy Department, UTT. Dr. Elgammal authored and co-authored over 47 Scholarly Technical Journals, and over 77 Refereed Conference Publications and three Engineering Book Chapters. In 2010, Dr. Elgammal has been elevated to senior member of Institute of Electrical and Electronics Engineers (IEEE), the world's largest professional association dedicated to advancing technological innovation and excellence for the benefit of humanity. His current Research areas include Power Systems and Electro-Technology, Motor Drives, FACTS Technology, Renewable/Alternate Energy Systems, Harmonics and Power Quality, Application of Intelligent Systems (Particle Swarm Optimization PSO, Fuzzy Logic, Neutral Networks, and Genetic Algorithms) to Power Systems, Renewable / Green Energy Systems and Electric Drives, Application of Power Electronics to Power Systems, Computer-Based Controllers. Dr. Elgammal has gained industrial and academic experience as well as participated in several technical consultations and professional experience.

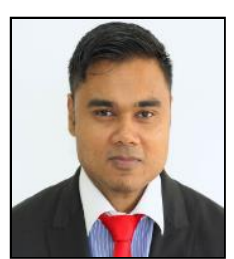

Curtis Boodoo currently holds the position of Assistant Professor in the Utilities Engineering Unit at the University of Trinidad and Tobago (UTT). He has been a faculty member at UTT since 2004 and Program Coordinator for the Electrical / Electronics Engineering Diploma program at the John Donaldson campus since 2008. He has contributed towards the development of the Sustainable Energy Implementation Plan 2021/2030 for Trinidad and Tobago, The National Energy Policy and the National Integrated Solid Waste Management Strategy. He has also represented UTT at the Renewable Energy and Energy Efficiency subcommittee of the Economic Development Board of Trinidad and Tobago. He currently holds the position of Expert in the Systems Evaluations Group (SEG4) - Low Voltage Direct Current Applications, International Electrotechnical Commission (IEC) and was a member of the Specifications Committee for Electrical Appliances. 